\title{
Very Fine-Grained Cu-0.4Mg Alloy Improving Intrauterine Device
}

Jiancun Rao ${ }^{1}$, Wen-An Chiou ${ }^{1}$ and Yufeng Zheng ${ }^{2}$

${ }^{1}$ Advanced Imaging and Microscopy Laboratory (AIM Lab), Maryland NanoCenter, University of Maryland, College Park, Maryland, United States, ${ }^{2}$ Department of Materials Science and Engineering, College of Engineering, Peking University, Beijing, China

The non-hormonal copper-containing intrauterine device ( $\mathrm{Cu}-\mathrm{IUD}$ ) is one of the most widely used contraceptives for human birth control [1] due to its safety, high effectiveness, affordability, and reversibility [2]. However, the burst release of cupric ions $\left(\mathrm{Cu}^{2+}\right)$ in the first few days of implantation prevents the continuation of the $\mathrm{Cu}^{2+}$ release in the conventional coarse-grained (CG) $\mathrm{Cu}-\mathrm{IUD}$. To maintain constant release of $\mathrm{Cu}^{2+}$ in the uterine over the lifespan of the $\mathrm{Cu}$-IUD and to improve cell and tissue biocompatibility, a newly designed very fine-grained (VFG) $\mathrm{Cu}-0.4 \mathrm{Mg}$ alloy was developed and tested. The purpose of this study is to investigate the microstructure of very fine-grained $\mathrm{Cu}-0.4 \mathrm{Mg}$ alloy in the role of suppressing the burst release of $\mathrm{Cu}^{2+}$ in $\mathrm{Cu}$-IUD using electron microscopy.

To investigate the corrosion behavior of the $\mathrm{Cu}$ and hence the release rate of $\mathrm{Cu}^{2+}$ in the intrauterine device, two kinds of $\mathrm{Cu}$ containing materials, pure $\mathrm{CG} \mathrm{Cu}$ rods $(99.99 \%)$ and VFG $\mathrm{Cu}-0.4 \mathrm{Mg}$ rods, were selected for this study. While pure CG Cu rods (99.99\%) were purchased from a commercial company, the VFG $\mathrm{Cu}-0.4 \mathrm{Mg}$ rods were laboratory fabricated via 8-pass equal channel angular pressing (ECAP) method. Thin discs cut from these two $\mathrm{Cu}$-containing rods were mechanically ground and polished. TEM specimen was prepared by further thinning a pre-thinned disc using a FIB (Tescan GAIA3) by in-situ liftout technique whereas a pre-thinned discs was further polished using a broad ion beam (Gatan PECS II) for electron backscatter diffraction (EBSD) study. The TEM study was carried out using a JEOL 2100F TEM/STEM equipped with Bruker EDS and Gatan EELS/GIF systems at the accelerating voltage of 200 $\mathrm{kV}$. A ThermoFisher (FEI) Helios G4 PFIB UXe DualBeam FIB/SEM equipped with an EBSD analyzer "CHANNEL 5" was employed for EBSD investigation.

TEM micrographs show a large grain-size difference between pure $\mathrm{CG} \mathrm{Cu}$ and VFG $\mathrm{Cu}-0.4 \mathrm{Mg}$ alloy (Fig. 1). TEM images of CG Cu depicted heterogeneous grain size, ranging from 1 to $20 \mu \mathrm{m}$ with random orientations. Many bend contours due to the bending/bulking of those very large $\mathrm{Cu}$ grains can easily be observed (Fig. 1a). On the other hand, the VFG Cu-0.4Mg alloy after 8-pass ECAP revealed elongated and relatively uniform grains with an average size of $300 \mathrm{~nm}$ that are preferentially oriented along the extrusion direction as compared to $\mathrm{CG} \mathrm{Cu}$ (Fig. 1b). Electron diffraction analysis showed that angles between (020) and (200), and (200) and (220) in [001] zone axis were $45^{\circ}$ each in CG Cu which is typical for the pure $\mathrm{Cu}$, while $45.3^{\circ}$ and $44.9^{\circ}$, respectively in VFG Cu- $0.4 \mathrm{Mg}$ alloy. The very small angles change between (020), (200), and (220) in [001] zone axis of VFG Cu-0.4 Mg alloy indicate lattice distortion that might have resulted from the effect of ECAP extrusion and/or the additional $\mathrm{Mg}$ in the alloy. EBSD results were consistent with the data obtained from the TEM study.

To understand the release behaviors of the metallic ions in these two $\mathrm{Cu}$ materials, long term immersion tests in simulated uterine fluid (SUF) up to 300 days were conducted (Fig. 2). Both $\mathrm{CG} \mathrm{Cu}$ and VFG Cu$0.4 \mathrm{Mg}$ alloy exhibited a rapid $\mathrm{Cu}^{2+}$ release within the first month followed by a steady release rate after 50 days' immersion. Despite the high release rate of $\mathrm{Cu}^{2+}(76.63 \mu \mathrm{g} /$ day $)$ in VFG Cu- $0.4 \mathrm{Mg}$ on the $1^{\text {st }}$ day, the release rate after 30 days' immersion remained rather constant at $15.88 \mu \mathrm{g} /$ day. This suggests that the addition of the more electrochemically active alloy element $\mathrm{Mg}$ with the high fraction grain boundary in VFG $\mathrm{Cu}-0.4$ alloy might inhibit the release rate of $\mathrm{Cu}^{2+}$. In addition, $\mathrm{Mg}$ in VFG $\mathrm{Cu}-0.4 \mathrm{Mg}$ might also play an important role in enhancing the biocompatibility and comfort of the Cu-IUD adoption [3].

* Corresponding author: yfzheng@pku.edu.cn 


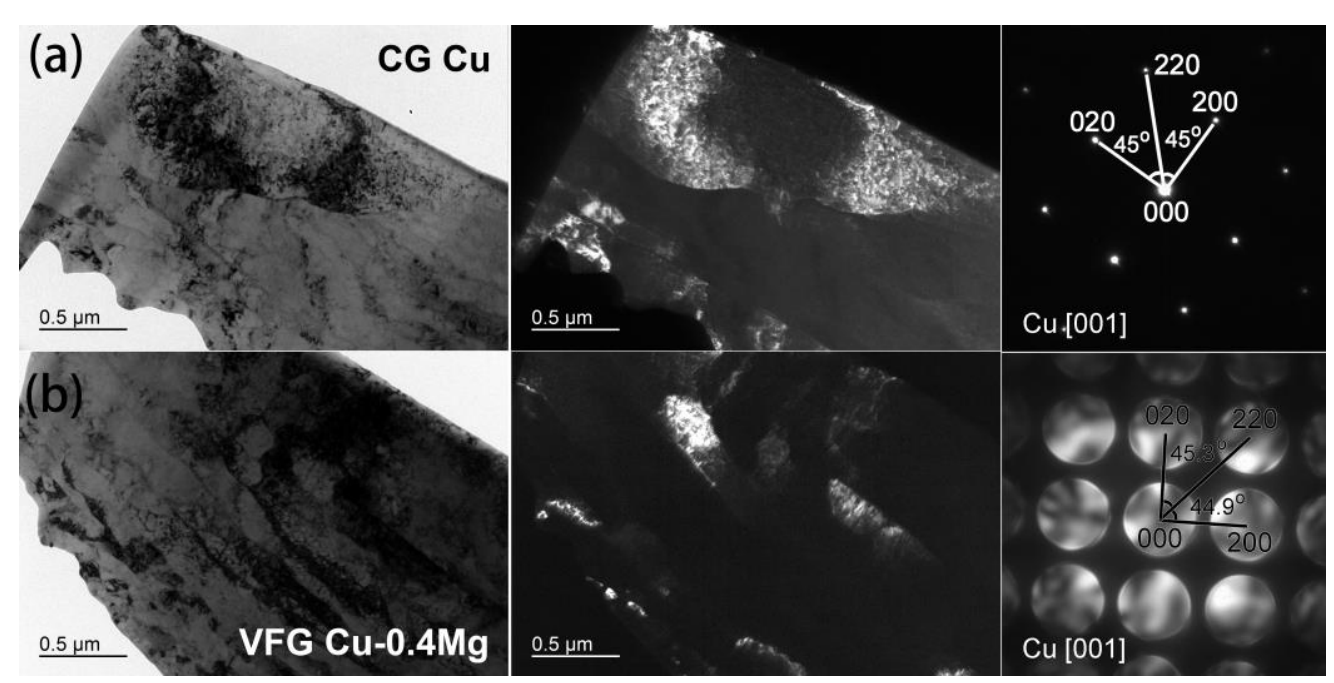

Figure 1. (a) TEM bright-/dark-field (left/central) micrographs, and SAD pattern (right) of CG $\mathrm{Cu}$ showing heterogeneous and randomly distributed large grain size with a typical FCC diffraction pattern. Note grains are so large that reveals bending/buckling as shown by bend contours. (b) TEM bright-/darkfield (left/central) micrographs, and a micro-diffraction pattern of VFG-0.4 Mg alloy revealing preferentially oriented very fine-grained materials with large amounts of defects after 8-pass ECAP extrusion.

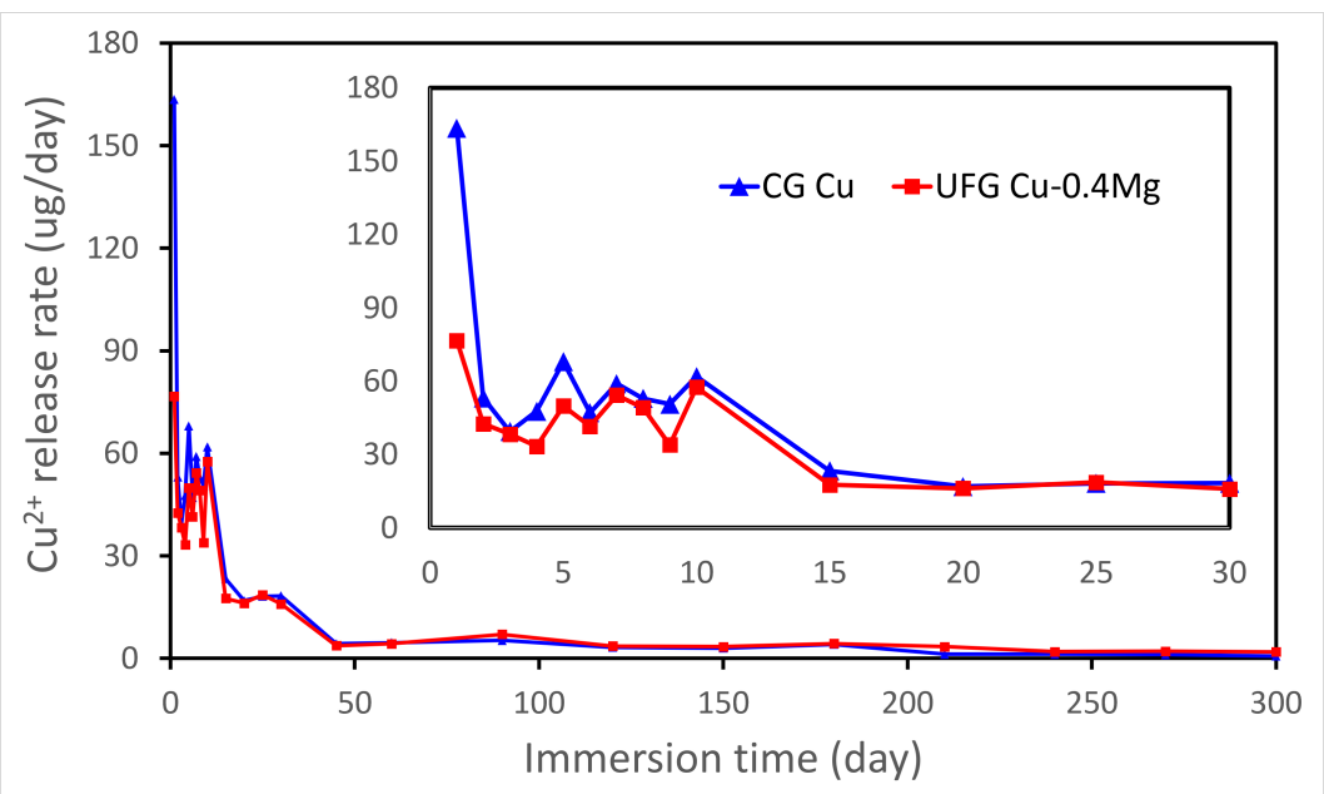

Figure 2. Comparison of cupric ion release rate of coarse-grained $\mathrm{Cu}$ and ultrafine-grained $\mathrm{Cu}-0.4 \mathrm{Mg}$ alloy incubated in SUF at $37^{\circ} \mathrm{C}$ for 300 days.

\section{References}

[1] D.M. Bastidas et. al, Corrosion Reviews 37(4) (2019) 307-320.

[2] K.M. Curtis and J.F. Peipert, New England Jour. Med 376(5) (2017) 461-468.

[3] TEM research was partially supported by the AIM Lab, Maryland NanoCenter at University of Maryland. 